\section{AURICULAR PAROXYSMAL TACHYCARDIA IN CHILDHOOD}

BY

TREVOR WRIGHT, M.D., D.C.H.

Paediatrician, Lincoln County Hospital ; Formerly Medical Registrar, Children's Hospital, Sheffield

In the adult, auricular paroxysmal tachycardia is characterized by a sudden onset and offset, a rapid heart rate (usually 160 to 180 beats a minute), and, more often than not, a regular rhythm. The disturbance is usually transient. It is the most common and least important type of paroxysmal arrhythmia, and is usually associated with an otherwise normal cardiac mechanism. The diagnosis is made with certainty by electrocardiogram. Calisthenic movements, of arm-stretching or body-bending, and vagal stimulation by pressure on the eyeball or carotid sinus are recommended as useful first measures and are often successful. Should such manœuvres fail, the drug of choice is methacholine.

In reviewing the literature, and in recording personal observations in cases of auricular paroxysmal tachycardia, it is hoped to make quite clear in how many respects the condition and its treatment differ in childhood from those in the adult.

Hubbard (1941) reviewed the literature in regard to the condition affecting infants. He found details of only 19 cases, and added nine from his own experience. Of these nine, he observed six in the same year, and could not help assuming that the condition was not as rare as the literature suggested.

The clinical records of a further 38 cases reported in the literature have been studied and summarized. In all but the first of these cases the diagnosis was confirmed and the heart rate counted by electrocardiogram. Six cases personally observed in the years 1948-51 have been added, in five of which the electrocardiogram tracing was interpreted as that of supraventricular tachycardia. No tracing was obtained in the first case.

Case 1

A male child aged 4 weeks refused feeds for one week and had laboured breathing for two days. The diagnosis before admission to hospital was pneumonia. Presenting signs were laboured breathing; cyanosis; liver enlarged two fingers below right costal margin; oedema present over feet. ankles, and sacrum; heart rate of approximately 300 a minute; and fine crepitations limited to the lung bases. No electrocardiogram or $x$-ray film of the chest was obtained before treatment.

Progress and Treatment.-Neostigmine, $0.125 \mathrm{mg}$., was given intramuscularly, and within 20 minutes the heart rate slowed to 120 . Clinical improvement ensued, and within 24 hours the infant was normal in all respects. Digoxin, $0.025 \mathrm{mg}$. daily, by mouth was given for four days and then discontinued. The infant remained well. There was no clinical evidence of congenital heart disease.

Follow-up.-The patient, when last seen two months after the initial illness, was clinically well, and the heart was noted to be normal in size, sounds, and rate.

\section{Case 2}

The mother of a male child aged 19 weeks noticed the infant's heart thumping when bathing or dressing him. Presenting signs were mild cyanosis; minimal oedema over feet, ankles, and sacrum; liver enlarged two fingers below right costal margin; heart enlarged; heart rate 280 ; and raised venous jugular pressure. $X$-ray examination of the chest showed generalized enlargement of the heart and clear lung fields. The electrocardiogram revealed supraventricular tachycardia with 2-1 A.V. response. In Fig. 1 the second $P$ waves can be seen on top of the $R$ waves in the lead CR1. In view of the A.V. block some cardiologists would interpret the tracing as auricular flutter.

Progress and Treatment.-Pressure was applied to the eyeballs and carotid sinus without benefit. Three intra-

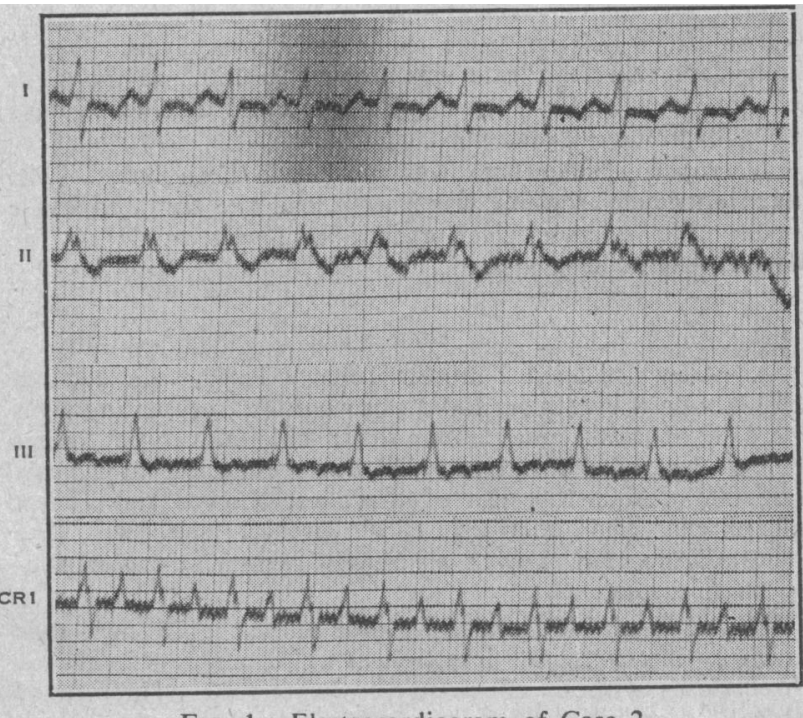

Fig. 1.-Electrocardiogram of Case 2

muscular injections of neostigmine of $0.125,0.125$, and $0.25 \mathrm{mg}$. at half-hourly intervals were then given without effect on heart rate or clinical picture. Following this, tincture of digitalis, 5 minims $(0.3 \mathrm{ml}$.) twice daily was given. for eight days, when the heart rate slowed to 115 , with clinical improvement. A maintenance dose of $2 \frac{1}{2}$ minims $(0.15 \mathrm{ml}$.) of tincture of digitalis was continued for some three months.

Follow-up.-The patient's condition was reviewed at intervals for 18 months after withdrawal of the digitalis. He remained clinically well and the heart was noted to be normal in size, sounds, and rate.

\section{Case 3}

A female child aged 3 months failed to gain weight and vomited. Presenting signs were enlarged heart with systolic murmur; enlarged liver, four fingers below right costal margin; oedema over feet, ankles, and sacrum; raised venous jugular pressure; and heart rate of 240 . No signs

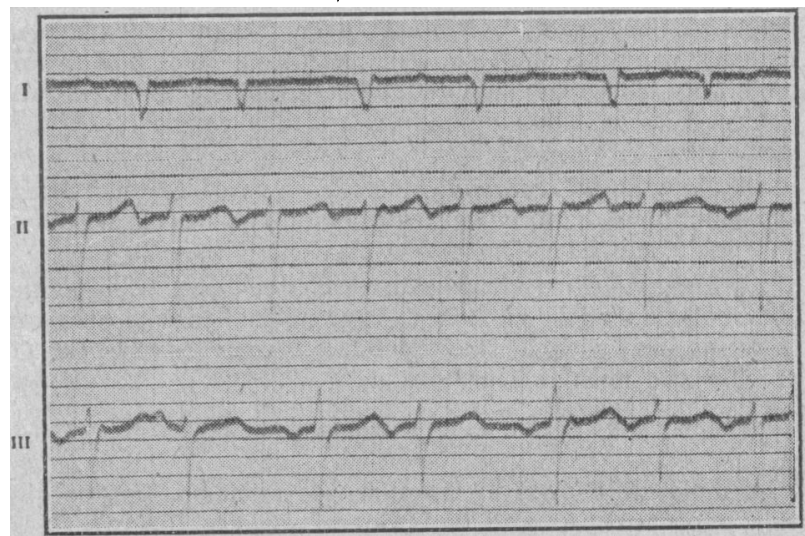

Fig. 2.-Electrocardiogram of Case 3. 
suggesting pneumonia were detected in the chest. An $x$-ray film of the chest showed consolidation in the right upper zone and an enlarged heart shadow.

The electrocardiogram was very difficult to interpret. Supraventricular tachycardia was present. Lead II was regular except for one beat, and inverted $P$ waves appear to precede each QRS complex, which is of normal type (Fig. 2). No definite evidence of conduction defect. In Lead III the rhythm is irregular, and, although most of the $P$ waves are inverted, one upright $P$ wave is clearly seen. Presumably this is due to a shifting pace-maker.

Progress and Treatment.-As well as penicillin, digoxin by mouth, $0.125 \mathrm{mg}$. three times daily, was given. Within four days the heart rate was slowed to 150 and the signs of cardiac failure were reduced. The child died seven days after beginning treatment.

Necropsy.-Pneumonia was present in both lungs. The interventricular septum was patent and the foramen ovale open. No microscopical examination was made of the cardiac conducting system.

\section{Case 4}

A male child aged 2 months refused feeds, vomited, and had laboured breathing and a poor colour. Presenting signs were right basal pneumonia, liver enlarged three fingers below the right costal margin, heart enlarged, and heart rate 300. An $x$-ray film of the chest showed right basal pneumonia and enlarged cardiovascular shadow. The electrocardiogram showed absolutely regular supraventricular tachycardia.

Progress and Treatment.-Neostigmine, $0.125 \mathrm{mg}$. , was given by intramuscular injection at half-hourly intervals for three doses without effect on the heart rate. Tincture of digitalis, $1 \mathrm{minim}(0.06 \mathrm{ml}$.) four times daily, was then given for eight days, when the heart rate slowed to 140 . Three days later the heart rate returned to the region of 300 . Digoxin, $0.125 \mathrm{mg}$. by mouth three times daily, was recommenced and continued for one week, resulting in reduction of the heart rate to 150 . After a further 12 days without treatment the infant became ill again with the heart rate and clinical picture as at the onset of his illness. Digoxin was readministered with good result, and the child was̀ sent home, having a maintenance dose of $0.125 \mathrm{mg}$. daily. He had no further cardiac disturbance, but six months after his initial illness he died of rapidly increasing hydrocephalus.

Necropsy.-Hydrocephalus was associated with scarring and thickening of the meninges, presumably due to an old inflammatory lesion and causing a blockage at the lower surface of the cerebellum. No macroscopic abnormalities were detected in the heart.

\section{Case 5}

A female child aged 2 years had a cough for two months after whooping-cough. On admission breath sounds were normal, and the heart rate 250 . There was mild cyanosis, but no enlargement of heart or liver and no oedema. An $x$-ray film of the chest showed clear lung fields and a normal cardiovascular shadow. The electrocardiogram was interpreted as showing auricular tachycardia with 1-1 response.

Progress and Treatment.-As the signs of cardiac defeat were minimal digitalis was withheld. The heart rate spontaneously slowed to normal over a period of 10 days.

Follow-up.-Two years after discharge from hospital the patient was well and the heart was normal in size on $x$-ray examination, with a rate of 82 a minute in the E.C.G. tracing and normal heart sounds.

\section{Case 6}

A male child aged 17 months was restless, slept poorly, had poor appetite, and had general malaise for two days.
Presenting signs were restlessness, a mild degree of cyanosis, liver enlarged two fingers below right costal margin, heart slightly enlarged, and heart rate approximately 300 ; no heart murmur was detected. An $x$-ray film of the chest showed generalized enlargement of the heart and heavy vascular markings in the lung fields. The electrocardiogram showed supraventricular tachycardia, rate 315 , rhythm regular.

Progress and Treatment.-Digoxin, $0.125 \mathrm{mg}$., by mouth, was given six-hourly. After 10 doses the heart rate suddenly slowed to within normal limits, with clinical improvement. The child went home, having a maintenance dose of digoxin, $0.125 \mathrm{mg}$. by mouth, on alternate days.

Follow-up.-Six months after discharge from hospital digoxin was discontinued, and after a further six months the patient was noted to be clinically well. The heart was normal in size on $\dot{x}$-ray examination, with a rate of 84 a minute in the E.C.G. tracing and normal heart sounds.

\section{Discussion}

\section{Cases in the Literature}

In this survey the details from a total of 66 cases are used. These cases consist of the 19 reviewed by Hubbard (1941), the 9 personally observed by him, and 38 recorded in the literature since 1941. I do not claim that the whole of the literature on the subject is reviewed.

The commonest recorded symptoms were vomiting in 16 and laboured breathing in 14 cases. The commonest signs observed were enlarged liver in 28 , cyanosis in 15 , pallor in 11 , and oedema in only 2 cases. The lowest heart rate recorded was 210 , and the fastest without heart block 365 . The duration of attacks varied between a few minutes and five months. Of associated diseases the most common were diphtheria and pneumonia. As a therapeutic measure digitalis was the most popular, being employed in some form in 19 of 40 cases. Of these 19 children, 14 recovered. Fourteen children received no specific therapy directed towards controlling the heart rate, and of these only four recovered.

Campbell (1947), when reviewing the subject in all age groups, advised that in cases without serious heart damage the order of choice in regard to drugs used in treatment is methacholine, neostigmine, carbachol, and quinidine. Methacholine alone was effective in two cases. The drug is usually given hypodermically, but has been given intravenously. The usual dose in children is $0.2-1 \mathrm{mg}$., but $6 \mathrm{mg}$. has been given in one dose. Atropine sulphate, 1/150 $1 / 100$ gr. $(0.4-0.65 \mathrm{~g}$.), is the antidote, and a syringe loaded with this preparation should always be in readiness when methacholine is to be used, as its administration in children is not without danger. Neostigmine was mentioned in the treatment of only one case. This drug may be given intramuscularly or intravenously, usually the former. The dose in children is $0.2-1 \mathrm{mg}$. Quinidine alone was effective in one case. In children the dose is of the order of $\frac{1}{4} \mathrm{gr}$. (16 mg.) 12-hourly, with a maintenance dose of $1 \mathrm{gr}$. (16 mg.) daily. With this drug there is always the possibility of idiosyncrasy, a risk which is considerable when dealing with an infant already usually gravely ill.

Cunningham and Schnitzker (1950) used phenylephrine with dramatic effect. There were short periods of cardiac arrest after its use. They gave the drug intravenously, and recommended $0.1 \mathrm{mg}$. at half-hourly intervals, increasing up to as large a dose as $0.5 \mathrm{mg}$.

\section{Present Series}

In these six cases the commonest symptoms were vomiting in three and laboured breathing in four. The commonest signs observed were enlarged liver in five, cyanosis in five, oedema in five, and pallor in three cases. The range of heart rate was between 240 and 315 . In Cases 2 and 4 the rapid heart rate persisted until the eighth day 
of treatment and then suddenly the rate was reduced. Pneumonia as an associated disease was present in Cases 3 and 4.

Only two drugs were used to reduce the heart rate-neostigmine and digitalis, the latter as tincture or digoxin. Neostigmine was effective in Case 1. The dose given was $0.125 \mathrm{mg}$. by intramuscular injection to an infant of 4 weeks. In the other five cases digoxin or tincture of digitalis by mouth was effective. Digoxin orally seemed to be the drug of choice. A suitable dose was $0.125 \mathrm{mg}$. repeated two or three times daily until the heart slowed. Even the smallest babies tolerated such a dose, and indeed it seemed necessary to control the rapid heart action.

\section{Summary}

Auricular paroxysmal tachycardia is less rare than is often supposed.

In the cases seen in hospital the so-called " paroxysm" usually lasted several days.

The common clinical picture in childhood is that of cardiac failure associated with an extremely rapid heart rate (200-350 beats a minute). The insidious onset of such failure is frequently missed in children unless looked for.

Pneumonia may be the assumed diagnosis, and indeed is often present in addition to the tachycardia. Both conditions demand treatment.

The incidence of congenital heart disease in association with auricular paroxysmal tachycardia seems to be quite low.

Digitalis would appear to be the drug of choice in treatment. Large doses are tolerated in infancy and seem necessary for recovery. A smaller maintenance dose for four to eight weeks should be given to prevent early recurrence of the tachycardia.

I wish to thank Dr. T. Colver and Professors R. S. Illingworth and E. J. Wayne, under whose care some of the cases were admitted to hospital; Dr. J. F. Goodwin for his advice, and especially for his interpretation of the E.C.G. tracings: and Dr. B. R. Eaton for his help in obtaining the tracings

BIBLIOGRAPHY

Baker, H. (1941). Canad. med. Ass., J., 45, 426

Bass, M. H. (1942). J. Mt Sinat Hosp., 8, 357.

Blackford, L. M., and Hoppe, L. D. (1943). J. med. Ass. Ga. 3247

Bloom, N., and Kendig, E. L., jun. (1946). J. Pediat., 28, 474

Burke, E, C., and Platou, E. S, (1947). J.-Lancet, 67, 211.

Campbell, M. (1947). Lancet, 2, 641, 681.

Cunningham, G. C., and Schnitzker, W. F. (1950). J. Pedilat., 37. 727

Garvin, J. A., and Kline, E. M. (1947). Amer. Heart J., 33. 362

Hobbs, L. F. (1941) Ibid., 21, 804

Howard, P. J (1945). J. Pediat., 26, 273

Hubbard, J. P. (1941). Amer. J. Dis. Child., 61, 687

— and Starbuck, G. W. (1943). Ibid., 65, 582.

Keagy, R. M., and Magee, R. S. (1941). Pent. med. J., 45. 44

Leys, D. (1945). Arch. Dis, Childh., 20, 44.

Neubauer, C. (1945). Brtt. Heart J., 7, 107.

Peterman, M. G. (1946. Amer. J. Dis. Child., 71, 53

Scott, E. P , and Limper, M. A. (1946). J. Pediat., 28, 96

Segall, H. N., and Goldbloom, A. (1942). Canad. med. Ass, J., 46, 233

Silverman, J. J., and Race, O. M. (1949). Amer. Heart J., 37, 1139.

- and Werner, M. (1950). J. Pediat., 37, 765.

Tarnower, H., and Lattin, B. (1942). N.Y. St. J. Med., 42, 805

Tourniaire, A., Guyot, R., and Rochas, J. (1947). Arch. Mal. Caur. 41). 230.

Werner, W. E., Caplan, J., and Morris, M. H. (1948). Amer. Heart J., 35 1001 .

Young, J. H. (1944). Med. J. Aust., 1, 538.

The film "Streptomycin Drugs in the Treatment of Tuberculosis" has been withdrawn from the B.M.A. Film Library by Messrs. E. A. Squibb and Sons, from whom it was held on loan, because the methods of treatment and dosages depicted therein are now out of date.

\section{EFFECT OF HYDRALAZINE IN HYPERTENSION}

\author{
BY
}

M. A. KHAN, M.B., M.R.C.P.Ed.

(From the Department of Medicine, Postgraduate Medical School of London, W.12)

Hydralazine (1-hydrazinophthalazine ; " apresoline") has recently been under investigation both in the laboratory and clinically as an antihypertensive drug. Pharmacologically, its exact action is not known. It is an antihistaminase and has a wide range of activity in antagonizing humoral pressor substances-that is, hypertensin, pherentasin (Schroeder, 1952), serotonin (Taylor et al. (1951), and noradrenaline (Freis and Finnerty, 1950). There is suggestive evidence of a central action on the hypothalamus (Gross et al., 1950; Craver and Yonkman, 1950) and on peripheral arterioles. It has been shown that, associated with a decrease in peripheral resistance-preferentially marked in the kidneys-and a decrease in blood pressure, there is a pronounced tachycardia and an increase in cardiac output due either to a central effect or to local action of the drug on the heart (Moyer et al., 1951). There is an increase in the renal blood flow without constant increase in the glomerular filtration rate (Mackinnon, 1952) or any increase in tubular resorption of glucose, indicating that no additional nephrons are activated by the increase in renal blood flow (Moyer et al., 1951). No previously known antihypertensive drug has been shown to have this combined effect of decreasing the blood pressure and increasing the renal blood flow.

\section{The Investigation}

Selection of Cases and Method of Recording.-In the present study the effect of hydralazine was observed on arterial hypertension in 12 cases-nine suffering from essential hypertension, one from hypertension complicating chronic pyelonephritis, and two from malignant hypertension. All had hypertensive symptoms. In two cases of essential hypertension (Cases 3 and 6) blood pressures showed wide fluctuations, often related to psychological disturbances. Auscultatory blood-pressure readings were taken frequently in upright, sitting, and recumbent positions during a control period of 3 to 13 days, and, after the drug was given, pressures were taken in the same positions at intervals for six hours ; averages of control readings, and these readings after the drug, are given in the Table overleaf.

Dosage.-Hydralazine was administered orally in all trials. A test dose of $25 \mathrm{mg}$. was first given, and the dose was gradually stepped up from $25 \mathrm{mg}$. eight-hourly to higher levels reaching $400 \mathrm{mg}$. three times a day, thus varying from 75 to $1,200 \mathrm{mg}$. a day in different patients. Every attempt was made to continue treatment unless it was considered futile or the side-effects were so unpleasant and persistent as to warrant discontinuation of the drug. The effect of the drug lasted from four to six hours, with a maximum at from one to two hours after administration. In addition to oral treatment, parenteral therapy with hydralazine in doses of $50 \mathrm{mg}$. intramuscularly was tried in two cases, only one of which is tabulated (Case 5). The effect of combined oral therapy with hexamethonium bromide and hydralazine, as suggested by Schroeder (1952), was studied in Cases 4, 7, 8, and 9. The maximum daily doses tried were $2,250 \mathrm{mg}$. of hexamethonium bromide and $450 \mathrm{mg}$. of hydralazine. 